\title{
DOSSIÊ "Georges Canguilhem, a história e os historiadores"
}

\section{História da medicina e história das ideias: de Sigerist a Canguilhem}

\author{
Tiago Santos Almeida \\ Doutorando em História Social na Universidade de São Paulo (USP) \\ tiagoalmeida@usp.br
}

Recebido em 09/04/2016. Aprovado em 30/04/2016.

Como citar este artigo: Almeida, Tiago S.. "História da medicina e história das ideias: de Sigerist a Canguilhem". Intelligere, Revista de História Intelectual, São Paulo, v. 2, n. 1 [2], p. 68-83. 2016. Disponível em

$<$ http://revistas.usp.br/revistaintelligere $>$. Acesso em dd/mm/aaaa.

Resumo: Historiadores da filosofia e da historiografia negligenciaram a relevância dos trabalhos de Henry E. Sigerist sobre história da medicina para a concepção canguilhemiana de historicização das ciências. Esse artigo pretende lançar alguma luz sobre as circunstâncias intelectuais que conectaram os dois mais importantes historiadores da medicina do século passado, rastreando a influência do livro de Sigerist Introduction à la Médecine sobre a técnica histórica de Canguilhem para investigação do pensamento médico.

Palavras-chave: Georges Canguilhem, Henry E. Sigerist, história das ciências, história da medicina, história das ideias.

\section{History of medicine and history of ideas: from Sigerist to Canguilhem}

\begin{abstract}
Historians of philosophy and historiography have consistently neglected the relevance of Henry E. Sigerist's works on history of medicine to Canguilhem's conception of the historicization of the sciences. This article aims to shed some light on the intellectual circumstances that connected two of the last century's most important historians of medicine, by following the influence of Sigerist's book Introduction à la Médecine upon Canguilhem's historical technique of the investigation of medical thought.
\end{abstract}

Keywords: Georges Canguilhem, Henry E. Sigerist, history of science, history of medicine, history of ideas. 
Entre 1955 e 1971, Canguilhem dirigiu o Institut d'bistoire des sciences et des techniques (hoje, Institut d'bistoire et philosophie des sciences), ocupando a cadeira que pertencia a Gaston Bachelard e, antes dele, a Abel Rey, o fundador do instituto que durante muito tempo foi o único do gênero na França. Nesses dezesseis anos, além de oferecer diversos cursos dedicados à história das ciências, Canguilhem publicou sua segunda tese doutoral, La formation du concept de réflexe an XVII et XVIII siècles; relançou sua primeira tese, de 1943, acrescida de novas reflexões, sob o título Le normal et le pathologique; reeditou uma versão ampliada da tese complementar La connaissance de la vie; apresentou conferências e escreveu dezenas de artigos dedicados à história das ciências da vida e da medicina, a maioria reunidos nos livros Études d'histoire et de philosophie des sciences, Idéologie et rationalité dans l'bistoire des sciences de la vie e no póstumo Écrits sur la médecine. Em 1970, Canguilhem dirigiu os dois volumes da obra coletiva Introduction à l'Histoire des Sciences, que reuniu os principais historiadores das ciências franceses e ficou conhecida como o "vade mecum do pequeno historiador das ciências", uma importante contribuição ao projeto de promoção da história das ciências a disciplina de primeiro escalão no ensino universitário francês. Em 1983, Canguilhem foi agraciado com a "Medalha George Sarton", mais prestigiosa honraria da área de história das ciências, concedida pela History of Science Society em reconhecimento "a uma vida de conquistas acadêmicas". E, ainda assim, não é evidente que possamos falar de Canguilhem como um historiador das ciências.

Em 1972, a revista Tonus publicou uma entrevista concedida por Canguilhem a François Proust. A entrevista, que esteve "perdida" durante muito tempo ${ }^{1}$, começa da seguinte maneira: "Professor Canguilhem, o que é a história das ciências?". A questão apenas parece abrupta; mas o momento não poderia ser mais oportuno. Esse é um dos últimos documentos com o imprimatur de Canguilhem antes da sua aposentadoria do cargo de professor de história e filosofia das ciências que ocupava na Sorbonne. "Eu não sou verdadeiramente um historiador das ciências", respondeu. "Sou um professor de filosofia que se interessa por certo número de questões, que são as relações entre a filosofia e a ciência e em particular aquelas sobre a fabricação, o nascimento, a importação e a exportação de certo número de conceitos interpretativos de funções biológicas"2. É sem dúvida intrigante a preocupação em se delimitar dos historiadores das ciências enquanto afirma se interessar por questões cujo lugar teórico de elaboração e resolução é a história das ciências. Mas são documentos como esses, encontrados em meio aos arquivos pessoais de Canguilhem, que tem reforçado certa releitura da sua obra, que questiona a imagem do "historiador das ciências".

Essa imagem começou a ser construída desde as primeiras apresentações gerais do pensamento de Canguilhem, publicadas por Pierre Macherey em 1964 e por Dominique Lecourt em 1971, além do famoso texto publicado por Michel Foucault em 1978. O texto de Lecourt, "La historia epistemologica de Georges Canguilhem", e o texto de Foucault, "Introduction by Michel Foucault", foram escritos para servir de prefácio às traduções argentina e estadunidense de Le normal et le pathologique, principal livro de Canguilhem. Já o texto de Macherey, "La philosophie de la science de Georges Canguilhem. Épistémologie et histoire des sciences", inicialmente publicado na revista La Pensée com uma apresentação de Louis Althusser que lhe rendeu grande visibilidade, vem sendo usado, desde 1982, como posfácio da tradução brasileira daquele livro. E não é apenas o sucesso que o livro de Canguilhem conheceu a partir dos anos 70 que está diretamente associado àqueles textos, mas a própria interpretação que se costuma fazer da sua obra. Para alguns comentadores, como Camille Limoges ou Jean-Pierre Séris, mais que destacar um interesse de filósofo por uma

1 Agradeço ao Prof. Camille Limoges, por ter me indicado a localização exata do documento, que ainda não havia sido catalogado pelo CAPHÉS à época das minhas pesquisas no centro arquivístico. Foi o Prof. Limoges quem anunciou a redescoberta dessa entrevista, "esquecida ou passada despercebida, provavelmente porque publicada numa revista profissional para médicos raramente frequentada por filósofos e historiadores" (Camille Limoges, "L'épistémologie historique dans l'itinéraire intellectuel de Georges Canguilhem". In: Epistemology and bistory from Bachelard and Canguilhem to today's history of science (Berlim: Max Planck Institute for the History of Sciece, 2012, preprint), 65.

2 G. Canguilhem, "La médecine et son histoire", Tonus, (Paris), 1972, 42. 
disciplina que até pouco tempo era um campo de investigação da Filosofia, os textos de Macherey, Lecourt e Foucault difundiram a ideia de que a história das ciências para Canguilhem era "uma vocação, uma segunda ou até mesmo uma primeira natureza".

A explicação para aquela imagem construída por Macherey, Lecourt e Foucault deve muito ao fato de que eles foram alunos de Canguilhem nos anos 60. A maioria dos testemunhos sobre Canguilhem vem de seus ex-alunos, que costumam ressaltar a "presença institucionalmente forte e brilhante" (palavras de Claire Salomon-Bayet ${ }^{4}$ ) na Sorbonne do professor de história e filosofia das ciências que, discretamente, ajudou a construir o ambiente intelectual francês da segunda metade do século XX. Pierre Bourdieu, em sua Esquisse pour une auto-analyse, se vangloria da afinidade de habitus mantida com Canguilhem, a "figura exemplar" e "verdadeiramente universal" do racionalismo francês, o "emblema totêmico", o "farol", o "maître à penser" com quem aprendeu "a conceber a possibilidade realística de viver de maneira diferente a vida intelectual"5. Em 1990, Canguilhem enviou a seguinte mensagem aos organizadores de um colóquio em sua homenagem: "Não me é possível, na minha idade, fazer outra coisa além daquilo que sempre fiz, ou seja, não é possível que eu considere aquilo que é chamado de minha obra como algo diferente da marca do meu ofício. É comovente que alguns dos meus antigos alunos o reconheçam"'. Não se trata de modéstia: os arquivos pessoais e de trabalho de Canguilhem, preservados no CAPHÉS, o Centre d'Archives en Philosophie, Histoire et Édition des Sciences da École Normale Supérieure de Paris, permitem comprovar que todos os textos de história das ciências tiveram origens nos cursos ministrados por Canguilhem.

O problema é que, para Limoges, as interpretações que fizeram de Canguilhem um historiador das ciências "por natureza" capturaram apenas um instantâneo da sua obra, um corte bastante limitado da sua vastíssima produção, restrito ao período em que já se pode imprimir em seus textos a marca da "epistemologia histórica". Quando o Essai sur quelques problèmes concernant le normal et le pathologique, tese de doutorado em medicina, foi publicado em 1943, Canguilhem já tinha 39 anos. Foi apenas aos 51 que ele obteve o doutorado em filosofia com a tese sobre a história do conceito de reflexo e assumiu seu posto na Sorbonne e seu cargo no Institut d'histoire des sciences et des techniques. Nesse intervalo, Canguilhem escreveu diversos artigos, sobre os mais variados temas filosóficos, que nem sempre foram levados em consideração pelos seus comentadores. Com o conhecimento de que se dispõe, hoje, da real extensão dessa produção, a constatação de Limoges é que o encontro de Canguilhem com a história das ciências é um acontecimento tardio da sua "história intelectual pessoal" cuja explicação reside menos na concretização de seu projeto filosófico "um duplo jogo de interrogações, de uma parte sobre o valor da verdade em relação aos outros valores, e de outra parte sobre a precariedade criadora do ser vivo"7 - do que na necessidade de cumprir de modo apropriado as exigências do seu ofício. Para Limoges, foram as novas funções de professor de História e Filosofia das Ciências e de diretor do Institut, assumidas em 1955, que "criaram nele a obrigação - e também multiplicaram as ocasiões - de assumir intensamente seu novo papel”. Em suma, Canguilhem teria sido historiador das ciências apenas enquanto foi professor de história das ciências na Sorbonne.

Um dos principais responsáveis pela publicação das obras completas de Canguilhem, e também seu ex-aluno, Limoges fala com a convicção dos números:

\footnotetext{
3 Jean-Pierre Séris, "L'histoire et la vie" em Georges Canguilhem: philosophe, historien des sciences. Actes du colloque (6-7-8 décembre 1990) (Paris: Albin Michel, 1993), 90.

$4 \mathrm{Na}$ apresentação ao número especial da Revue d'bistoire des sciences dedicada ao tema "Georges Canguilhem et son temps" (Paris), [vol.] 53, 1 (2000): 7.

5 Pierre Bourdieu, Sketch for a Self-analysis (Chicago: The University of Chicago Press, 2008), 26-34, passim.

6 Mensagem lida por Michel Deguy na "Allocution de clôture" do colóquio "Georges Canguilhem, philosophe, historien des sciences", organizado pelo Collège international de philosophie. Ver nota 3.

7 Camille Limoges, "L'épistémologie historique dans l'itinéraire intellectuel de Georges Canguilhem", 65.
} 
Os títulos em história das ciências representam pouco mais de $15 \%$ da produção total de Canguilhem; a epistemologia cerca de $27 \%$. As publicações filosóficas sem caráter propriamente epistemológico, que são as mais numerosas (pouco mais de 30\% do total), são também aquelas cuja abundância foi a mais precoce e cujo crescimento numérico permanece o mais uniforme (com uma aceleração ao longo dos anos de aposentadoria, período em que os trabalhos de história das ciências, pelo contrário, enfrentaram uma desaceleração). ${ }^{8}$

Defender a ruptura da identidade entre a obra e o ofício, como propôs Limoges, não significa negar inteiramente que Canguilhem foi um historiador excepcional, mas pretende reavaliar o papel da história das ciências no seu percurso intelectual para fazer emergir do cinza dos documentos a figura resplandecente do filósofo "por inteiro", que escreveu sobre o pensamento científico, mas também sobre lógica, moral, pedagogia, política etc. Essa ambição é sustentada pela leitura renovada da sua obra, mas considerando agora textos que durante muito tempo sequer foram incluídos no corpus canguilhemiano. Em 1985, uma edição da Revue de métaphysique et de morale inteiramente dedicada a Canguilhem informou que sua obra começava em 1943, com a publicação da tese de doutorado em medicina, o Essai sur quelques problèmes concernant le normal et le pathologique. A bibliografia crítica organizada por Camille Limoges em $1994^{9}$ foi a primeira a mencionar o Traité de logique et de morale, publicado por Canguilhem e Camille Planet em 1939, além de informar sobre dezenas de textos virtualmente inéditos, publicados sob o pseudônimo G. C. Bernard na Libre propos, a revista fundada por Alain, e até mesmo clandestinamente, quando Canguilhem atendia pelo codinome Lafont, Médico Tenente e Chefe do Estado-Maior político da Résistance durante a ocupação da França pelos nazistas. Isso sem falar nos manuscritos, milhares de páginas que, por determinação de Canguilhem, não poderão ser publicadas, mas estão à disposição dos pesquisadores no CAPHÉS e servem de apoio às novas interpretações.

Apesar de sua profissionalização como historiador das ciências ter início apenas nos anos 50, na Sorbonne, o pesquisador que voltasse sua atenção para os cursos de filosofia ministrados por Canguilhem já a partir de 1941 na Faculté des Lettres de Strasbourg perceberia o crescente interesse pela teoria do conhecimento e pela história das ciências e das técnicas. Nas suas anotações para as aulas, a reflexão sobre o problema geral da história da filosofia é animada por um conjunto de questões particulares que o acompanhará ao longo da década: 1) Qual é a relação entre a filosofia e a história da filosofia?; 2) Qual é a relação entre a história da filosofia e a história das ciências?; 3) Qual é a relação entre a história das ciências e a história das ideias?. Mas por que um filósofo se interessaria especificamente por tais questões? Encontramos uma pista no manuscrito "Histoire de la philosophie et histoire des sciences", espécie de exercício pessoal escrito em 1945. "Podemos dar uma definição a priori da filosofia, independente da sua história?”, Canguilhem pergunta. A resposta é elaborada através do tema da "historicidade", quer dizer, o fato de que a história de uma atividade é constitutiva da forma dessa atividade: "Se não podemos separar a filosofia da sua história, a definição do conceito de filosofia depende da sua história". Resposta que levanta o problema da delimitação do domínio: "O que fazemos entrar nessa história?”. O problema, ele continua, é que a filosofia não tem um objeto especial, constatação que o leva à reafirmação da famosa fórmula inscrita no Essai, de 1943: "A filosofia é uma reflexão para a qual toda matéria estrangeira é boa, e diríamos de bom grado, para a qual toda boa matéria deve ser estrangeira". Assim, Canguilhem propõe que a melhor solução para o filósofo é estender a ideia de uma "história constitutiva"

8 Ibid, 64.

9 Camille Limoges, "Critical bibliography" em Georges Canguilhem, A vital rationalist: selected writings from Georges Canguilhem, François Delaporte (ed.), trad. Arthur Goldhammer (Nova Iorque: 1994), 385-454. 
da filosofia às relações que mantém com “outras funções da consciência humana: religião, técnica, arte, ciência... ${ }^{10}$

As "funções da consciência" são um antigo novo problema da filosofia de Canguilhem. Na obra publicada, elas aparecem num livro pouco conhecido e destinado ao ensino de filosofia, o Traité de Logique et de Morale, publicado em 1939 com Camille Planet. Nele, podemos ler que a ciência é "uma função do espírito humano capaz como tal de entrar em relação com as outras funções" "11, a saber, a técnica, a religião e a arte. Canguilhem e Planet propõem tentar "compreender historicamente como a mesma relação [entre a ciência e as outras funções] influencia o trabalho científico e em quais condições é garantido o 'progresso' desse trabalho". Existem muitos indícios nos manuscritos e outros documentos de Canguilhem de que essa noção de "funções da consciência" pode ser articulada à noção de "utensilagem mental" [outillage mental], apresentada por Lucien Febvre e Abel Rey em 1937, no primeiro volume da monumental Encyclopédie française, intitulado L'outillage mental: Pensée. Language. Mathematiques: "É impossível conhecer a utensilagem [outillage] do pensamento sem fazer a sua história. O pensamento (o sujeito) está em ação e reação contínua com aquilo que ele quer pensar (o objeto): uma luta e uma conquista"12. Se a sugestão causa estranhamento, vale dizer que, no livro Les inquietudes de la raison, Enrico Castelli Gattinara explicou que os historiadores que viriam a fundar os Annales (Febvre e Marc Bloch), "recusando toda fratura entre história e ciência, se dirigiam àqueles que, como Rey, tentavam articular a necessidade da história em uma reflexão sobre a ciência"13, ou seja, o grupo de filósofos e historiadores reunidos no Centre de Synthèse, de Henry Berr, justamente de onde veio o primeiro reconhecimento da contribuição teórica das ideias de Canguilhem à historiografia das ciências.

O levantamento documental para edição das CEuvres complètes recuou o início da produção intelectual de Canguilhem para o ano de 1926, fazendo aparecer o "Canguilhem avant Canguilhem", expressão de Jean-François Braunstein ${ }^{14}$, já de uso corrente entre os comentadores que se dedicam aos textos anteriores ao Essai. Apesar dessa valorização dos primeiros escritos de Canguilhem, Braunstein não acompanha Camille Limoges até o fim em sua interpretação sobre as razões da chegada de Canguilhem aos problemas da história das ciências. Para Braunstein - outro membro do Comitê Editorial das CEuvres complètes de Canguilhem; co-diretor do primeiro tomo, que abrange o período de 1926 a 1939 - os escritos do "primeiro Canguilhem" nos levam a "melhor compreender a evolução ulterior da obra (...), o que permite retificar a imagem corrente que faz de Canguilhem um puro historiador das ciências ou um simples continuador da obra de Bachelard"15. Retificar uma imagem significa desnaturalizá-la, indicando, por um lado, a história da sua constituição e as condições que a tornaram possível, e, por outro, rastreando pelos textos a formação de um pensamento para fazer aparecer o historiador na evolução de uma obra, entendida não apenas como signo de um itinerário pessoal, mas também como síntese histórica de uma cultura intelectual.

10 Além daquela pergunta sobre a possibilidade de uma definição a priori da filosofia, Canguilhem levanta outros dois problemas: 1) "A bistória da filosofia deve utilizar o método geral da história naquilo que diz respeito ao estabelecimento do documento ou do texto. Trabalho preparatório: uma vez o documento datado/situado e estabelecido, resta interpretá-lo"; 2) "A bistória da filosofia é a bistória daquilo que está morto, perimido, desaparecido ou daquilo que é vivo? (...) História das doutrinas ou bistória dos problemas". Canguilhem propôs que a atualidade vem do observador, e não da obra em si. Em seguida, anotou que essa questão deveria ser relacionada ao "problema mais original do valor das ciências históricas. Cf. Nietzsche e Aron". Anexo ao manuscrito, havia um documento datilografado, longo trecho da intervenção de Alexandre Koyré no debate "Sur la notion d'bistoire de la philosophie" (do qual participaram também Léon Robin, Henry Berr, Jean Wabl e Leon Brunschvicg), publicado no Bulletin de la Société française de Philosophie em junho de 1936. Nesse debate, Koyré defendeu que a história da filosofia é uma história do presente.

11 Georges Canguilhem e Camille Planet, Traité de Logique et de Morale. In: Georges Canguilhem, Oeuvres complètes, tome I: écrits philosophiques et politiques 1926-1939. (Paris: Vrin, 2011), 659.

12 Abel Rey e Lucien (eds.), L'Outillage mental: Pensée, langage, mathématiques (Paris: Société de gestion de l'Encyclopédie française, 1937), 3 .

13 Enrico Castelli-Gattinara, Les inquiétudes de la raison: Epistémologie et histoire en France dans l'entre-deux-guerres (Paris: Vrin, 1998), 81

14 Jean-François Braunstein. "Canguilhem avant Canguilhem”, Revue d'histoire des sciences, [vol.] 53, 1 (2000): 9-26.

15 Braunstein, "Canguilhem avant Canguilhem”, 10. 
Não é possível pensar a problemática histórica na obra de Canguilhem limitando o olhar aos textos de Canguilhem, sem considerar o próprio debate historiográfico. Se não podemos concordar que Canguilhem é um historiador das ciências "por natureza", também não podemos dizer que seu interesse pela história das ciências é fruto do contato com a epistemologia de Bachelard, cujos efeitos se tornam mais visíveis em Canguilhem a partir da tese sobre o conceito de reflexo, de 1955. Já nos anos 40, Canguilhem refletia sobre os métodos e os objetos da história das ciências e, antes de Macherey, Lecourt e Foucault, foram os próprios historiadores das ciências, também nos anos 40, que notaram a contribuição original de Canguilhem para o debate historiográfico.

\section{Sigerist na França}

Segundo o Dictionnaire de la pensée médicale, organizado por Dominique Lecourt, as três correntes da historiografia médica do século XX que marcarão de maneira duradoura o modo de escrever e pensar a disciplina são "as Escolas" germano-americana, polonesa e francesa, cujos principais representantes seriam, respectivamente, Henry Sigerist, Ludwik Fleck e Georges Canguilhem. O verbete "Histoire de l'histoire de la médecine", escrito por Christiane Sinding, não chega a explorar as relações possíveis entre essas correntes, ainda que admita que, em diferentes aspectos, "Fleck está próximo das posições que Canguilhem desenvolverá mais tarde de maneira independente"16. Essa aproximação entre as correntes francesa e polonesa foi explorada, a partir dos trabalhos de seus principais representantes, por Jean-François Braunstein no artigo "Deux philosophies de la médecine: Canguilhem e Fleck". Apesar do fato de Canguilhem e Fleck não terem se conhecido, Braunstein consegue trazer à luz semelhanças espantosas entre suas teses epistemológicas. "Essas similitudes dizem respeito aos pontos centrais de suas filosofias, quer se trate de suas respectivas críticas das teorias do conhecimento, de suas concepções de história das ciências, da questão das relações entre ciência e não-ciência ou mesmo da questão da verdade", escreveu ${ }^{17}$. Não temos notícia de uma tentativa de aproximação semelhante entre as escolas francesa e germano-americana, fato sem dúvida surpreendente pois Canguilhem, no seu principal livro, reconhece a importância da leitura de Henry Sigerist, provavelmente o mais ilustre historiador da medicina do século passado. No Essai de 1943, as referências a Sigerist saltam aos olhos, a propósito de questões fundamentais, rodeadas pelos mais elogiosos adjetivos e escritas em tom de reconhecimento de uma dívida intelectual. A tal ponto que, se Braunstein fez do desconhecimento mútuo de Fleck e Canguilhem o ponto de partida de sua reflexão, a dificuldade aqui seria determinar, por um lado, aquilo que Canguilhem deve à sua leitura de Sigerist e, por outro, as semelhanças que teriam começado a ser elaboradas ao longo de uma reflexão prévia àquela leitura.

Esse encontro de Canguilhem com a obra de Sigerist não deve causar estranhamento. Embora toda a obra de Sigerist tenha sido redigida em alemão e inglês, o francês era a sua língua materna. Sigerist nasceu e passou toda a sua infância em Paris, que, nas primeiras linhas de sua inacabada autobiografia, ele descreveu como a "mais maravilhosa cidade na Terra". A cultura científica francesa não era estranha a Sigerist, e nem ele o era a certos círculos

16 Christiane Sinding, "Histoire de l'histoire de la médecine" em Dominique Lecourt (dir.), Dictionnaire de la pensée médicale (Paris, PUF, 2004), 577.

17 Jean-François Braunstein, "Deux philosophies de la médecine: Canguilhem et Fleck" em A. Fagot-Largeault, C. Debru, M. Morange (orgs.), Philosophie et médecine. En hommage à Georges Canguilhem (Paris: Vrin, 2008 ), 64. O tema das aproximações possíveis entre Canguilhem e Fleck também foi abordado por Mauro Lúcio Leitão Condé durante a conferência "Entre o normal e o patológico: Ludwik Fleck, Georges Canguilhem e a gênese da epistemologia histórica", apresentada no colóquio "Os objetos da história das ciências", realizado na Universidade de São Paulo no dia 8 de abril desse ano, e organizado pelo Grupo de Pesquisa em História Intelectual. 
intelectuais parisienses. No início dos anos 1920, Sigerist era membro da Société d'bistoire de la pharmacie e da Societé française d'histoire de la médecine, e sua obra já era uma referência comum nas publicações sobre a história das ciências e a história da medicina na França no momento em que Canguilhem elaborava sua tese. Apesar da interpretação fixada atualmente sobre Sigerist, dos trabalhos de sociologia e história social da medicina e da saúde pública que fizeram dele a estrela da manhã da moderna historiografia médica, em seus primeiros trabalhos na década de 20 Sigerist defendia que a história da medicina deveria se ater a um "estrito método filológico histórico", como afirmou em um dos seus primeiros textos programáticos, "Aufgaben und Ziele der Medizingeschichte", de $1922^{18}$. No começo daquela década, seu livro mais celebrado na França, como em toda a Europa, era o Studien und Texte zur frümittelalterlichen Rezeptliteratur, que não passava de uma coletânea de antidotários medievais, seguidos de uma breve análise do seu conteúdo, da classificação das receitas, modo de administração e comentários sobre as fontes da compilação. Em 1923, no Bulletin de la Société d'Histoire de la Pharmacie, Ernst Wickersheimer celebrou o emprego rigoroso da análise filológica, considerando o livro de Sigerist "uma obra notável"19.

A situação mudaria em poucos anos. Em 1929, o próprio Wickersheimer lançou, no Bulletin de la Societé Française d'Histoire de la Médecine, um ataque público contra os trabalhos recentes de Sigerist. O artigo de Wickersheimer, "Civilisation et maladie: d'après un article récent", como anuncia seu subtítulo, foi escrito a propósito de outro artigo, intitulado "Kultur und Krankheit", publicado por Sigerist alguns meses antes na revista Ky/klos. "Ponto de partida: a doença é largamente influenciada pelas condições gerais da existência. Ideia muito justa, embora não muito nova" ${ }^{20}$, diz Wickersheimer sobre o texto de Sigerist. A originalidade no estabelecimento das relações entre "a patologia de uma época" e "o gênero de vida que então levavam as diversas classes da sociedade”, segundo Wickersheimer, pertence a Émile Littré, que havia dedicado grande interesse e várias páginas à história das epidemias. Como prova dessa originalidade, Wickersheimer destaca o artigo "Des grandes épidémies", publicado por Littré na Revue des deux mondes em 1836. Assim, atribuía a Sigerist apenas um "curioso" esforço de "perseguir a ideia de Littré até as suas últimas consequências", a saber, "uma sincronia necessária entre os fatos da história das doenças e os fatos da história geral”21.

A sugestão de continuidade entre as ideias de Sigerist e as de Littré parecia plausível no momento em Wickersheimer escrevia. Em 1930, ano seguinte à publicação do artigo de Wickersheimer, o Instituto de História da Medicina da Universidade de Leipzig, do qual Sigerist era o diretor, adquiriu através de leilão um manuscrito de Littré sobre Charles Daremberg. O manuscrito, datado de fevereiro de 1862, foi publicado no Sudhoffs Archiv für Geschichte der Medizin com uma breve apresentação de Sigerist, na qual podemos ler já nas primeiras linhas a seguinte avaliação: "A moderna história da medicina teve seu ponto de partida na França. Littré e Daremberg são seus porta-vozes"22. Sigerist acreditava que o manuscrito de Littré era uma espécie de carta de recomendação para a primeira cadeira de história da medicina na França, que viria a ser criada em 1870, antes mesmo da criação da primeira cadeira de história geral das ciências. Com o apoio de Littré, Daremberg foi de fato eleito para a Faculté de Médecine e, nas décadas seguintes, encorajou os historiadores a perseguirem uma história filológica e erudita, atenta à interpretação interna dos textos médicos - uma orientação que Sigerist seguira fielmente no começo da sua carreira.

18 Owsei Temkin, "Henry E. Sigerist and aspects of medical historiography" em Elizabeth Fee e Theodore M. Brown (eds.) Making medical history: the life and times of Henry E. Sigerist. (Baltimore/Londres: The Johns Hopkins University Press, 1997), 124.

19 Ernest Wickersheimer, "Henry E. Sigerist, Studieuse und Texte zur frühmittelalterlichen Rezeptliteralur", Bulletin de la Société Française d'Histoire de la pharmacie, (1923): 201.

20 Ernest Wickersheimer, "Civilisation et maladie. D'après un article récent", Bulletin de la Société Française d'Histoire de la Médecine, [vol.] XXIII, 1-2 (jan-fev, 1929): 31.

21 Ibid.

22 Henry E. Sigerist, "Littré über Daremberg” em Sudhoffs Archiv für Geschichte der Mediə̨in. [vol.] XXIII, 4, (out., 1930): 382. Sobre as contribuições de Daremberg à história da medicina, of. Jean-François Brainstein, "Daremberg et les débuts de l'histoire de la médecine en France", Revue de l'bistoire des sciences, [vol.] 58, 2, (2005): 367-387. 
Para Wickersheimer, Littré havia comprovado com sucesso que a origem das doenças epidêmicas poderia ser investigada a partir "das mudanças enfrentadas pelas formas de vida dos homens" "23, enquanto Sigerist cometia um grave erro ao fazer coincidir, sem explicar as razões, o surgimento de certas doenças e alguns episódios decisivos da história geral: a peste bubônica (dita "peste de Justiniano") e a peste negra com o começo e o fim da Idade Média, respectivamente; a sífilis com a origem do Renascimento; a doença inglesa do suor (sudor anglicus) com o fim da Guerra das Duas Rosas... Procedendo assim, ironizou Wickersheimer, apenas em torno da história da Inglaterra Sigerist já teria uma enormidade de temas a sugerir a seus alunos em Leipzig: bastava descobrir fatos patológicos que coincidissem com a Carta Magna (1215), com a ruptura de Henrique VIII com Roma (1533) ou com a execução de Jaime I (1649). "Falando francamente, eu prefiro o bom e velho Plínio", concluiu Wickersheimer, afinal, "se ele acreditou que um cometa pressagiou a Guerra Civil, pelo menos ele não pretendeu que o cometa causou a Guerra; e tampouco disse que foi a Guerra que engendrou o cometa"24.

Mas o texto de Sigerist, - cujo título Wickersheimer repete, "Civilisation et maladie" -, não é apenas um "artigo recente" publicado em uma revista qualquer. Kyklos era o anuário do Instituto de História da Medicina da Universidade de Leipzig, fundado por Karl Sudhoff em 1906, e dirigido por Sigerist desde 1925. O Instituto era subdividido em quatro departamentos: Medicina Geral, Farmacologia, História Cultural e Patologia. "Kultur und Krankheit", na verdade, sequer era um artigo, o resultado de uma investigação minuciosa sobre um problema específico, mas a descrição do programa de trabalho estabelecido por Sigerist para o Departamento de Patologia, que se dedicava ao estudo das relações de estilo entre as doenças e a cultura. Por conta da Guerra, esse trabalho realizado em Leipzig só foi apresentado de modo sistemático numa série de conferências pronunciada na Cornell University em $1940^{25}$ e publicada sob o título Civilization and disease ${ }^{26}$, livro traduzido no Brasil, com um esclarecedor texto introdutório de Everardo Duarte Nunes. Em 1929, aquilo que Wickersheimer condenava em "Kultur und Krankheit" eram os sinais do afastamento de Sigerist da sombra paterna de Karl Sudhoff (a quem também pagava tributos pela sua abordagem filológica da história da medicina) e da aproximação das ideias de Oswald Spengler e sua morfologia cultural27.

Em "Kultur und Krankheit", Sigerist apenas ensaiava os primeiros movimentos de uma renovação que abriria a história da medicina para além da história das ciências. Ao relacionar doença e civilização, Sigerist pretendia, por um lado, demonstrar que certas doenças, especialmente as epidemias, influíam sobre as transformações políticas e econômicas das nações e, ao mesmo tempo, tinham consequências sobre e derivavam da vida cultural dos povos: não é o Renascimento que faz nascer a sífilis, mas o estilo do homem renascentista que ajuda a disseminá-la. Oitenta e cinco anos depois, nossa avaliação é forçosamente diferente da que fez Wickersheimer: dado o estado atual da historiografia médica, sabemos que Sigerist não estava simplesmente revelando sincronias entre fatos patológicos e fatos históricos, mas abrindo uma nova perspectiva, tentando inaugurar novas possibilidades e mesmo objetos de investigação para a história da medicina. Foi a partir dessa nova perspectiva historiográfica que, justamente numa de suas visitas a Paris, na primavera de 1930, Sigerist escreveu Einführung in die Medizin, o livro mais importante do seu período europeu, e responsável por apresentar a um público mais amplo a perspectiva histórica que desenvolvia em Leipzig desde que assumiu a direção do Instituto de História da Medicina.

23 Ernest Wickersheimer, “Civilisation et maladie. D'après un article récent”, 32.

24 Ibid.

25 Ingrid Kästner, “The Leipzig Period, 1925-1932” em Elizabeth Fee e Theodore M. Brown (eds.) Making medical history: the life and times of Henry E. Sigerist, 50.

26 Henry E. Sigerist. Civilization and disease (Ithaca: Cornell University Press, 1945). [Civilização e doença, trad. Marcos Fernandes da Silva Moreira. (São Paulo: Hucitec-Sobravime / Campinas: SindiMed, 2011)].

27 Elizabeth Fee e Theodore M. Brown, "Intellectual legacy and political quest: the shaping of a historical ambition", em Elizabeth Fee e Theodore M. Brown (eds.) Making medical history, 186. 
Quando Einfübrung in die Mediz̨in foi publicado na Alemanha, em 1931, Sigerist já gozava de grande prestígio entre os historiadores das ciências. Além de uma década de experiência profissional na história da medicina, da Universidade de Zurique à Universidade de Leipzig, Sigerist era um militante da história das ciências, tendo fundado em 1928, ao lado de Abel Rey, George Sarton, Charles Singer, Aldo Mieli, Karl Sudhoff e Lynn Thorndike, o Comitê Internacional de História das Ciências, que, no ano seguinte, após um primeiro congresso em Paris, se tornaria a Academia Internacional de História das Ciências - cuja primeira sede foi a biblioteca do Centre de Synthèse, fundado por Henri Berr e ponto de encontro de importantes historiadores das ciências, como Alexandre Koyré, Hélène Metzger e Pierre Brunet. Tudo isso, aliado a uma produção de prosa fácil, mas sem abrir mão da erudição, já havia garantido para Sigerist um grande público leitor.

Os textos de Sigerist repercutiam na França e, de acordo com a revista Archeion, órgão oficial do Comitê e depois da Academia, "basta anunciar os livros de Sigerist para fazer nascer em nossos leitores o desejo de lê-los e possui-los"28. De fato, Einführung in die Medizin foi um grande sucesso editorial à época do seu lançamento, imediatamente traduzido para diversas línguas. A tradução francesa Introduction à la médecine foi publicada já em 1932, poucos meses após a publicação do original alemão. É sobretudo a originalidade da perspectiva histórica de um manual de introdução aos estudos médicos que explica a recepção entusiasmada de Introduction à la médecine na França. Em 1933, Pierre Ménétrier, antigo presidente da Société française d'Histoire de la Médecine, apresentou assim o livro de Sigerist à Académie nationale de médecine: "o professor Sigerist (...) pensou que a melhor maneira de iniciar o jovem estudante, o futuro médico, nas ciências que ele deve aprender, bem como aos deveres e às obrigações de sua profissão, era lhe mostrando seu desenvolvimento histórico, sua lenta evolução e seu progresso". Para Ménétrier, no livro de Sigerist "a história da Medicina não é mais apenas uma pura curiosidade retrospectiva, mas se torna um elemento de ensino científico e profissional da mais evidente atualidade" 29 . Vejamos as primeiras linhas do livro de Sigerist:

Esse livro se dirige antes de tudo aos jovens homens que escolheram a carreira médica e que se encontram no início dos seus estudos. Ele tenta pintar em traços largos um quadro da medicina, as tarefas que ela se propõe, os problemas que ela evoca. Ele visa dar noções fundamentais, se servindo amplamente para isso do método histórico. Existe melhor procedimento para compreender uma ideia que fazer o leitor participar da sua elaboração? ${ }^{30}$

\section{Canguilhem e a "gênese das hipóteses"}

Síntese das pesquisas realizadas durante meia década à frente do Instituto de História da Medicina em Leipzig, Introduction à la médecine, não era um livro de história, mas uma obra de iniciação destinada aos estudantes nos primeiros anos do curso médico - situação em que o próprio Canguilhem se encontrava na segunda metade da década de 30, ao mesmo tempo em que dava aulas de filosofia em Toulouse. Esse contexto nos ajuda a restabelecer o papel central do Essai sur quelques problèmes concernant le normal et le pathologique ${ }^{31}$, tese de doutorado em

28 Archeion. Archivio storico della scienæa, Organe officiel du Comité international d'histoire des sciences, (Roma), [vol.] XIV, t. 3, (1932).

29 Bulletin de Académie nationale de médecine, ano 97, $3^{\text {a }}$ série, t. CIX, 2, (Janeiro 1933): 34.

30 Henry E. Sigerist, Introduction à la medicine, trad. Maurice Ténine (Paris: Payot, 1933), Prefácio.

31 O livro Le normal et le pathologique, publicado em 1966, é a reunião de dois textos sobre a mesma questão, escritos com vinte anos de intervalo. A primeira parte do livro corresponde à tese de doutorado em medicina, de 1943, Essai 
medicina defendida e publicada em 1943, no processo que chamamos historicização das ciências - antes mesmo de conferir "uma secreta unidade e uma sólida coerência a toda obra histórico-epistemológica", como argumentou François Delaporte ${ }^{32}$. Tudo isso num livro onde não há sequer uma menção a Bachelard e no qual Canguilhem manifestou o desejo de não ser confundido: “(...) não pretendemos passar por historiador da medicina. Se na primeira parte colocamos o problema em perspectiva histórica, foi unicamente por razões de mais fácil inteligibilidade"33. A preocupação acompanhava uma avaliação severa da historiografia de sua época, que Canguilhem percebia demasiadamente dedicada aos estudos dos grandes médicos e seus feitos: "Não temos nenhuma pretensão de erudição no campo da biografia"34, ironizou. Evitava, assim, que os capítulos de sua tese dedicados a Broussais e Claude Bernard fossem confundidos com os panegíricos habituais dos historiadores da medicina.

No Essai, Sigerist é frequentemente evocado por Canguilhem, a propósito da "animação" da anatomia, do isolamento social experimentado pelos doentes, da relatividade individual do normal biológico, da relação entre clínica e endocrinologia etc. Mas é sobretudo "o modo habitual de proceder" de Sigerist, a inclusão das descobertas e ideias científicas "na história intelectual da civilização" 35 ou, para dizer de maneira mais clara, a relação intrínseca que Sigerist estabelece entre a história das ciências e a história das ideias, que chama a atenção de Canguilhem. O desenvolvimento dessa proposição na obra de Canguilhem abriu o caminho para a elaboração da noção do objeto da história das ciências como um objeto cultural, e, imediatamente na obra de Canguilhem, fez deslocar o interesse histórico das respostas para as questões. Ou seja, em vez de buscar escrever a história das conquistas da medicina e das ciências da vida, Canguilhem passou a se perguntar pelas condições de possibilidade histórica de um determinado problema e as condições que permitiram que uma teoria fosse aceita como verdadeira. É o que Canguilhem faz a propósito da teoria da doença de Leriche, apoiado em Sigerist:

"A medicina", disse Sigerist, "é uma das ciências mais estreitamente ligada ao conjunto da cultura, toda transformação nas concepções médicas sendo condicionadas por transformações nas ideias de uma época". A teoria [da doença de Leriche,] que acabamos de expor, ao mesmo tempo médica, científica e filosófica, comprova perfeitamente essa proposição [extraída do livro Introduction à la Médecine]. Parece-nos que ela satisfaz simultaneamente a diversas exigências e postulados intelectuais do momento histórico da cultura no qual ela foi formulada. ${ }^{36}$

Essa maneira de problematizar a história das ciências foi apresentada por Sigerist a propósito da descoberta por Harvey da circulação do sangue em 1628. "De onde vem que a ideia da função entra na medicina precisamente no começo do século XVII? Por que não mais cedo? Por que não mais tarde? Quais circunstâncias lhe deram nascimento?”, perguntou Sigerist antes de convidar a "situar Harvey com mais precisão na história intelectual europeia" 37 . Assim como muitas ideias publicadas no Introduction à la Médecine, esse problema tinha sua origem nas pesquisas desenvolvidas no Instituto em Leipzig. Foi em 1928 que Sigerist apresentou a conferência mais tarde publicada sob o título "William's Harvey position in the history of european thought", na qual defendia a tese de que "a história da circulação do sangue, como a história da ciência em geral, e da medicina em particular, demonstra a íntima aliança com a história da cultura"38. Segundo Sigerist, o objeto da fisiologia é o movimento, uma ideia que não poderia ter sido concebida em outro momento da história intelectual europeia posto que "a fisiologia e a ideia funcionalista na medicina são produtos do barroco" e

sur quelques problèmes concernant le normal et le pathologique. A segunda parte, escrita entre 1963 e 1966, recebeu o título Nouvelles réflexions concernant le normal et le pathologique. É no texto de 1943 que aparecem as referências a Sigerist mencionadas nesse artigo.

32 François Delaporte, "La problématique historique et la vie" em Georges Canguilhem: philosophe, historien des sciences, 226. 33 Georges Canguilhem, Le normal et le pathologique (Paris: Presses Universitaires de France, 2010), 8.

34 Canguilhem, Le normal et le pathologique, 8.

35 Ibid, 136

36 Ibid, 61.

37 Sigerist, Introduction à la Médecine, 40.

38 Sigerist, "William's Harvey position in the history of european thought" em Felix Marti-Ibañez (ed.), Henry E. Sigerist On the history of medicine (Nova Iorque: MD Publications, 1960), 185 
"Harvey é o primeiro a incorporar o conceito do barroco"39. Apoiado nas ideias do historiador da arte Heinrich Wölfflin, Sigerist defenderá que o barroco era uma forma de pensamento que reinava sobre todos os domínios do espírito da época. Para Sigerist, Harvey não era diferente de Galileu, em quem teria se produzido, de maneira análoga à da arte de Michelangelo, "uma evolução que o conduziu da ideia estática à ideia dinâmica" ${ }^{40}$. No Essai, Canguilhem demonstrou ter se impressionado com essas ideias:

Sigerist não separa a ciência da vida, nascida em 1628, da concepção geral, digamos filosófica, da vida que se expressa então nas diversas atitudes do indivíduo diante do mundo. As artes plásticas em primeiro lugar, do fim do século XVI e começo do XVII, fixaram o estilo barroco, liberaram o movimento por toda parte. Ao contrário do artista clássico, o artista barroco não vê na natureza senão aquilo que é inacabado, virtual, ainda não circunscrito. "O homem do barroco [escreveu Sigerist] não se interessa por aquilo que é, mas por aquilo que vai ser. O barroco é infinitamente mais que um estilo na arte, é a expressão de uma forma de pensamento que reina nessa época em todos os domínios do espírito: a literatura, a música, a moda, o Estado, o modo de viver, as ciências". Os homens do começo do século XVI, fundando a anatomia, privilegiaram o aspecto estático, delimitado, da forma viva. Aquilo que Wölfflin diz do artista barroco, que ele não vê o olho, mas o olhar, Sigerist diz do médico no começo do século XVII: "Ele não vê o músculo, mas sua contração e o efeito que ela produz. Eis como nasce a anatomia animata, a fisiologia. O objeto dessa ciência é o movimento. Ela abre as portas ao ilimitado. Cada problema fisiológico conduz às fontes da vida e permite as fugas sobre o infinito”. Harvey, ainda que anatomista, não via no corpo a forma, mas o movimento. Suas pesquisas não são fundadas sobre a configuração do coração, mas sobre a observação do pulso e da respiração, dois movimentos que só cessam com a vida. ${ }^{41}$

Canguilhem jamais abandonará a ideia contida nessa frase: "Sigerist não separa a ciência da vida, nascida em 1628, da concepção geral, digamos filosófica, da vida que se expressa então nas diversas atitudes do indivíduo diante do mundo". Pierre Macherey, em 1964, na primeira análise de conjunto da obra de Canguilhem que se tem notícia, afirmou que o objetivo da tese de medicina de 1943, o Essai sur quelques problèmes concernant le normal et le pathologique, é "mostrar em que terreno ao certo se constituiu a fisiologia, 'o espírito da fisiologia nascente' (ver a chamada a Sigerist, a propósito da obra de Harvey): uma ciência das condições de saúde". Curiosamente, quando decidiu reeditar seu texto em 2009, para a coletânea De Canguilhem à Foucault, la force des normes, Macherey excluiu a referência a Sigerist. Mais recentemente, Claude Debru, no artigo "Georges Canguilhem et la rationalité du pathologique”, lembra, en passant, porém mais decidido, que a ideia de Sigerist do movimento como objeto da fisiologia, a partir de uma concepção barroca, foi determinante para a argumentação de Canguilhem, para quem esse "espírito" da fisiologia nascente teria sido incorporado na definição da fisiologia como "ciência das condições de saúde"

Consideremos ainda o seguinte exemplo, também retirado da tese de 1943. Canguilhem propôs um exame histórico da tese amplamente difundida no século XIX segundo a qual os fenômenos patológicos seriam apenas variações quantitativas, e não qualitativas, dos fenômenos normais do organismo. Antes, porém, de passar à crítica dessa teoria, Canguilhem apresentou as chamadas concepções ontológica e dinâmica da doença, que enxergam a doença ora como a luta contra um ser estranho que invade o homem, ora como a luta interna de forças que se afrontam no homem. "As doenças de carência e todas as doenças infecciosas ou parasitárias fazem a teoria ontológica marcar um ponto”, escreveu Canguilhem. Por outro lado, "as perturbações endócrinas e todas as doenças marcadas pelo prefixo dis reafirmam a teoria 
dinamista ou funcional". A concepção ontológica da doença pretende ser capaz de localizar o mal e combatê-lo. É a ideia de doença que atinge o homem, trazida de fora, e que, portanto, pode ser expulsa dele. Pasteur, afirma Canguilhem, deve muito do seu sucesso ao fato de suas teorias conterem uma representação ontológica do mal, o micróbio, entidade externa, visível, localizável (ao contrário dos miasmas) e, mais importante, combatível. Já na concepção dinâmica, a doença não pode ser localizada; ela está na totalidade do homem que perdeu sua harmonia interna, ainda que por alguma alteração no seu meio. Porém, nessa concepção, a doença é tanto a desarmonia quanto o esforço da natureza para obter um novo equilíbrio, o que exige uma medicina expectante, que tolere ou reforce essa terapêutica espontânea. Duas concepções de doença, dois tipos de otimismo: na técnica humana e na ação da natureza ${ }^{43}$.

Essa diferenciação entre a concepção ontológica e a concepção dinâmica das doenças não é uma ideia original de Canguilhem. Foi novamente no livro Introduction à la médecine, de Sigerist, que Canguilhem afirmou ter encontrado "uma explanação sumária e magistral de toda essa evolução das ideias médicas”, que vai da medicina egípcia - a partir da qual houve uma "generalização da experiência oriental das afecções parasitárias, combinando-a com a ideia de doença-possessão" - e da medicina grega - segundo a qual "a natureza (physis), tanto no homem como fora dele, é harmonia e equilíbrio” - até a formação, no século XIX, de uma teoria que via doença e saúde como variações quantitativas dos mesmos fenômenos fisiológicos.

Canguilhem usa a palavra "dogma" para falar da teoria sobre a identidade qualitativa entre o normal e o patológico, mas não para depreciá-la, e sim para "fazer com que sua repercussão e seu alcance sejam bem apreendidos" (a palavra "dogma” já havia sido empregada no caso, citado há pouco, das teorias microbianas das doenças contagiosas de Pasteur). A filosofia da medicina, diz Canguilhem, costuma ser buscada mais nos livros de literatura que nos livros de medicina, e não é possível negligenciar a difusão das ideias de Comte nos meios médicos, científicos e literários, tampouco as relações entre o naturalismo literário do século XIX e as doutrinas médicas e biológicas de Claude Bernard. Pode-se objetar que, difundida na civilização, transposta de sua origem intelectual para outros domínios da cultura, uma tese científica dificilmente manteria sua integridade, e que a deformação parece mesmo inevitável riscos aos quais um historiador das ciências como Canguilhem, a quem já se acusou de internalista e de fóssil conceitual, aparentemente não deveria se expor. $\mathrm{Na}$ verdade, para Canguilhem, esse é um dos principais méritos da história das ciências escrita em relação com a história das ideias: "diríamos que as deformações que ela [a tese] sofre no meio cultural podem revelar sua significação essencial”44.

Ora, Canguilhem atribui a Comte a autoria do "princípio de Broussais", e não a autoria da tese segundo a qual as doenças seriam apenas sintomas do "excesso ou falta de excitação dos diversos tecidos abaixo ou acima do grau que constitui o estado normal" 45 . Em relação a essa concepção nosológica o "dogma" comteano seria uma "deformação". Segundo Canguilhem, a identidade entre os fenômenos normais e patológicos aparece ao longo de toda a "evolução intelectual" de Comte, ou seja, do período preparatório do Curso de filosofia positiva (1830-1842), ao Sistema de política positiva (1851-1854), suas duas obras mais importantes. Comte aderiu publicamente àquele princípio em 1828, numa resenha do livro De l'irritation et de la folie,

43 Não raro esse “otimismo apaziguador” fez com que o pensamento médico oscilasse entre uma concepção e outra. No Brasil, Sérgio Arouca, em O dilema preventivista, constata, apoiado em Canguilhem, que a concepção dita "ecológica" de doença que caracteriza a medicina preventiva é, na verdade, a reunião das concepções ontológica e dinâmica: agentes externos são os causadores das doenças contagiosas, mas favorecidos por um desequilíbrio, seja do hospedeiro ou do meio. Assim, o conceito ecológico de doença seria duplamente otimista, "já que é sempre possível eliminar e (ou) equilibrar” em Sérgio Arouca, O dilema preventivista: contribuição para a compreensão e crítica da medicina preventiva (Tese de doutorado, Universidade Estadual de Campinas, 1975), 157-160, passim.

44 Canguilhem, Le normal et le pathologique, 17.

45 Auguste Comte, Examen du Traité de Broussais sur l'irritation, 1828, apêndice ao Système de politique positive, t. IV, 216, APUD Canguilhem, Le normal et le pathologique, 18-19. 
de Broussais. Segundo Canguilhem, desde então, a tese de que as doenças são sintomas da mudança de intensidade na ação dos estimulantes indispensáveis à saúde teria assumido um papel de axioma geral na filosofia de Comte, que lhe concedeu o mesmo "valor dogmático" atribuído à lei de Newton, mas à sua maneira. Canguilhem mostrará que o "princípio de Broussais" também foi investido de autoridade por Comte na ordem política. Mais que isso, ele argumenta, foi o valor político do princípio de Broussais que levou Comte a reconhecer, retroativamente, seu valor dogmático para a biologia. Foi essa operação, o uso particular da tese - tornada "princípio" - de Broussais na filosofia positiva que permitiu que Comte praticamente reivindicasse para si a paternidade da ideia. No Sistema de política positiva Comte afirma que:

Esse tratado [o Traité philosophique d'astronomie populaire, 1844] baseia-se no grande princípio cuja descoberta tive de atribuir a Broussais, porque sobressai do conjunto de seus trabalhos, embora somente eu tivesse elaborado sua formulação geral e direta. (...) Além de sua eficácia direta para as questões biológicas, ele [o princípio] constituirá, para o sistema geral da educação positiva, uma vantajosa preparação lógica aos processos análogos para a ciência final. Pois o organismo coletivo, em virtude de sua complexidade superior, comporta perturbações ainda mais graves, mais variadas e mais frequentes que a do organismo individual. Não tenho medo de assegurar que o princípio de Broussais deve ser estendido até esse ponto, e já o apliquei nesse campo para confirmar ou aperfeiçoar as leis sociológicas. Contudo, a análise das revoluções não poderia esclarecer o estudo positivo das sociedades, sem que haja, a esse respeito, a iniciação lógica resultante dos casos mais simples apresentados pela biologia. 46

Canguilhem explicou que não foi de maneira aleatória que escolheu os textos de Comte e Claude Bernard, entre tantos outros autores, talvez até mais citados, para falar sobre a teoria da identidade entre os estados normal e patológico. "É considerável a influência desses dois autores sobre a filosofia, a ciência e talvez ainda mais sobre a literatura", explicou. ${ }^{47}$ Sem minimizar o fato de que o Essai é um texto de filosofia da medicina, entendemos que, apoiado em Sigerist, Canguilhem começava a elaborar, já em 1943, uma nova maneira de refletir historicamente sobre as ciências da vida. Ainda que o tenha feito "unicamente por razões de mais fácil inteligibilidade", a novidade não passou despercebida, ao menos não pelos historiadores de ofício.

Nos anos seguintes à publicação do Essai, a maior parte dos resenhistas se limitaram a ver exatamente aquilo que Canguilhem disse que o livro é: um estudo filosófico que toma por objeto uma matéria estrangeira, a medicina, para tratar de dois problemas humanos concretos, a relação entre as ciências e as técnicas e a relação entre o normal e as normas. Mas, em 1947, portanto quatro anos após a publicação da tese, Pierre Brunet publicou uma resenha do Essai no número inaugural da Revue d'Histoire des Sciences. "Não sendo um estudo histórico, esse trabalho, cuja primeira parte é inteiramente centrada em torno dos nomes de Comte e de Claude Bernard, é suscetível (...) de interessar aos historiadores das ciências", escreveu ${ }^{48}$. Consideremos o lugar institucional dessa resenha, a Revue d'Histoire des Sciences, criada pelo próprio Brunet, a pedido de Henry Berr, como órgão oficial da Seção de História das Ciências

46 Comte, Loc. cit.

47 Em La volonté de puissance, $\int 533$, por exemplo, Nietzsche cita a seguinte passagem das Leçons sur la chaleur animale, de Claude Bernard: "A saúde e a doença não são dois estados essencialmente diferentes, como acreditaram os antigos médicos, e como ainda creem alguns práticos. Não se deve fazer deles princípios distintos, entidades que disputam entre si o organismo vivo e que fazem dele o teatro de sua luta. Essas são velharias médicas. Na realidade, existem apenas diferenças de grau entre esses dois modos de ser; o exagero, a desproporção, a desarmonia dos fenômenos normais constituem o estado doentio". Da leitura de Claude Bernard, Nietzsche conclui que "o valor de todos os estados mórbidos consiste no fato de demonstrarem sob uma lente de aumento certas condições que, apesar de normais, são dificilmente visíveis no estado normal."

48 Pierre Brunet, "Georges Canguilhem, Essai sur quelques problèmes concernant le normal et le pathologique. Compte rendu”, Revue d'bistoire des sciences, [vol. 1], 1 (1947): 90. 
do Centre de Synthèse. A publicação do primeiro número, em 1947, aconteceu num período de transição entre dois projetos do Centre de Synthèse, o projeto filosófico da primeira metade do século passado, quando se tratava de situar as ciências na história, e aquele que caracterizaria os anos 60 e 70 na França, a constituição da História das Ciências como campo disciplinar. Brunet, que acumulava as funções de diretor da Revue d'Histoire des Sciences e da Seção de História das Ciências do Centre de Synthèse, localizou no Essai de Canguilhem ideias relevantes para esses dois projetos.

Favorecendo o projeto disciplinar, Brunet viu na abordagem histórica de exemplos precisos retirados da fisiologia e da patologia a confirmação de que "vários problemas científicos não se explicam verdadeiramente senão através da história das ciências, e que esta, consequentemente, está longe de possuir apenas um valor de simples curiosidade histórica" 49 (lembremos que a relevância para o conhecimento e a prática médica também foi o principal mérito reconhecido à abordagem histórica de Sigerist). Esse foi o principal argumento mobilizado por Brunet em um texto programático publicado no número seguinte da mesma revista sob o título "L'Histoire des Sciences dans l'enseignement", dedicado à defesa da institucionalização da História das Ciências no ensino francês, dos liceus às universidades. Quanto ao projeto de inserção das ciências na história, questão de teoria das ciências tanto quando de teoria da história das ciências, Brunet afirmou ter encontrado no livro de Canguilhem "uma ideia interessante" que ele cita diretamente da primeira parte do Essai: "A história das ideias não pode ser necessariamente superposta à história das ciências", afirmou Canguilhem. "Porém, já que os cientistas, como homens, conduzem sua vida em um meio e em companhias não exclusivamente científicos, a história das ciências não pode negligenciar a história das ideias." 50

Tendo participado diretamente da organização dos arquivos do CAPHÉS e da publicação dos inéditos, é natural que Camille Limoges se empenhe, como ele mesmo reconhece, em estabelecer uma periodização da obra de Canguilhem. Não nos resta dúvida que essa insistência com a classificação interna dos textos fez com que Limoges descartasse os esforços historiográficos de Canguilhem no Essai, uma obra de "filosofia biológica" ou de "filosofia médica". Diante daquela resenha de Brunet, Limoges viu apenas o que servia à sua classificação; entendeu que, já na época do lançamento do Essai, os leitores não se "enganavam" sobre a natureza do livro: "Não sendo um estudo histórico...". A partir dessa frase de Brunet, todo o resto pareceu-lhe de menor importância. Assim, Limoges minimizou o reconhecimento, por Brunet, da perspectiva histórica de Canguilhem sobre as ideias de Broussais e Claude Bernard, afirmando serem semelhantes às análises encontradas nos livros de Émile Meyerson ou Léon Brunschvicg, a quem ninguém ousa acusar de historiadores das ciências.

Em sua argumentação, Limoges ainda lembra que o artigo "La theorie cellulaire", que compõe a segunda parte, nomeada "História", do livro La connaissance de la vie, foi publicado originalmente em 1946 com um subtítulo excluído da reedição de 1952, que, supostamente, revelaria sua verdadeira natureza: "Du sens et du valeur des théories scientifiques". "Em 1946, no sumário da revista, esse artigo havia sido classificado numa seção intitulada 'Filosofia das ciências", pondera Limoges. "De maneira que o único artigo que daria a uma parte de La connaissance de la vie um caráter francamente histórico aparece de maneira equívoca" ${ }^{151}$. De nossa parte, preferimos encontrar o lugar dos textos numa história viva, e não numa classificação. Como já afirmaram outros importantes comentadores, como François Delaporte e Claude Debru, o artigo sobre a teoria celular, escrito apenas dois anos após o Essai, é o

49 Ibid, 91.

$50 \mathrm{Idem}$.

51 Camille Limoges, “L'épistémologie historique dans l'itinéraire intellectuel de Georges Canguilhem”, 61. 
primeiro texto no qual Canguilhem reflete sistematicamente sobre a história das ciências, seus objetos e métodos:

A história das ciências recebeu até o presente momento na França mais encorajamentos do que contribuições. Seu lugar e seu papel na cultura geral não são negados, mas eles são bastante mal definidos. Seu sentido é mesmo flutuante. Deve-se escrever a história das ciências como um capítulo especial da história geral das ciências? Ou, antes, devemos pesquisar nas concepções científicas de um determinado momento uma expressão do espírito geral de uma época, uma Weltanschaunng? O problema de atribuição e de competência está em suspenso. Essa história parte do historiador enquanto exegeta, filólogo e erudito (isso sobretudo para o período antigo) ou, antes, do cientista especialista, apto a dominar enquanto cientista o problema do qual ele retraça a história?52

Canguilhem segue fazendo questões cada vez mais incisivas: devemos rastrear até os começos uma questão científica e fazer a história como o progresso daquela questão até sua forma atual? Basta encontrarmos um documento ou ideia ultrapassada, velha, para dizermos que fazemos história? E qual o valor para as ciências de uma história das ciências assim elaborada? A história das ciências não estaria, assim, reduzida a um museu de horrores, no qual são exibidos apenas os erros cometidos no passado, antes que a verdade científica viesse à luz? O artigo La théorie cellulaire é apenas o primeiro dos textos de Canguilhem onde aparece a denúncia contra uma concepção dogmática de ciências, mais ainda, contra "uma concepção dogmática da cultura científica, uma concepção dos 'progressos do espírito humano' que é

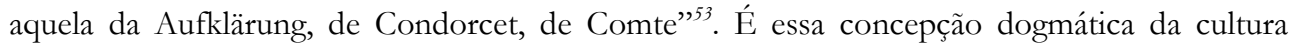
científica que, para Canguilhem, fundamenta o preconceito segundo o qual aquilo que foi dito no passado está errado, segundo o qual a anterioridade cronológica é sinônimo de inferioridade lógica. É essa tese positivista que, como lembra Canguilhem, sustenta as páginas de história das ciências da famosa Introduction à la médecine experimentale de Claude Bernard, onde lemos que "a ciência do presente está portanto necessariamente acima da ciência do passado, e não há razão para buscar um crescimento da ciência moderna nos conhecimentos dos antigos." Ainda segundo Claude Bernard, "As teorias dos antigos, necessariamente falsas, pois abarcam os fatos descobertos desde então, não poderiam ter nenhum benefício real para as ciências atuais". Em La théorie cellulaire, o objetivo de Canguilhem é restituir uma dignidade teórica ao pré-científico, defendendo uma continuidade entre certos objetos biológicos e suas primeiras formulações e imagens míticas. Vale a pena considerar a reavaliação recente desse texto de 1946 proposta por Claude Debru, também um ex-aluno de Canguilhem, uma avaliação que reforça nosso argumento sobre a presença, desde os anos 40, de uma preocupação teórica sobre as relações entre história das ciências e história das ideias:

Vemos se formar nesse trabalho bastante seminal de Canguilhem sobre a teoria celular uma prática da epistemologia sobre a qual, me parece, certos intérpretes de Canguilhem (eu me incluo) não insistiram suficientemente. A história das teorias e dos conceitos, que formará a vulgata da epistemologia histórica, que nos ensina que as teorias nascem de teorias preexistentes, não pode se dissociar do exercício da imaginação teórica. $O$ que se passa antes do famoso corte epistemológico é tão importante quanto o que se passa depois. Mas o mais essencial do texto sobre a teoria celular não é seu conteúdo epistemológico. Ele se encontra na constatação da conexão e da circulação das ideias. A ciência,

52 Georges Canguilhem, La connaissance de la vie (Paris: Vrin, 2006), 53-54

53 Ibid, 54. 
nesses textos, não aparece como um processo fechado, uma hiperespecialização cada vez mais minúscula. As ideias científicas, a filosofia das ideias científicas (mais até que a filosofia das ciências, expressão que eu nunca compreendi muito bem) estão em comunicação direta com muitos outros domínios que aqueles domínios de pertinência direta. ${ }^{54}$

Durante muito tempo, a "problemática histórica" na obra de Canguilhem foi estudada como uma reflexão desenvolvida alheia ao trabalho dos historiadores profissionais. A abertura dos seus arquivos e a publicação das suas obras completas começa a mudar essa opinião, ainda que lentamente. Parece-nos que obviedade da questão - a aproximação entre história das ciências e história das ideias - para o leitor contemporâneo, após incontáveis transformações no campo da história das ciências, somada à internalização da leitura dos textos de Canguilhem, como antídoto contra a "influência" bachelardiana, impediram que a maioria dos comentadores apreciasse adequadamente a importância da reflexão sobre a "conexão e a circulação das ideias" apresentada no Essai (e no artigo sobre a teoria celular, como admite Debru) para o desenvolvimento da obra ulterior. Razão pela qual acreditamos que o tema da historicização das ciências na obra de Canguilhem ganha ao ser tratado como um problema de história intelectual e não de história da filosofia. Pois, sem abrir mão da compreensão interna da obra de determinado autor, a história intelectual busca situá-lo no contexto de ideias que garantiu as condições de sua emergência e para o qual sua obra está inteiramente voltada. Sem querer atentar contra a grandeza de Nietzsche, a história intelectual só existe porque não aceita a possibilidade de pensamentos extemporâneos.

Em 1943, portanto antes da aproximação com Bachelard e da marca da epistemologia histórica, Canguilhem já havia começado a elaborar uma técnica histórica própria às ciências da vida e à medicina, capaz de dar conta desses novos objetos inscritos no epíteto que lhe foi atribuído por Raymond Aron: "Doutor em medicina, historiador do pensamento médico e biológico". E essa técnica histórica que vemos aparecer na obra de Canguilhem nos anos 40 está diretamente ligada à sua leitura de Sigerist, àquela forma de questionamento das ideias científicas elaborada inicialmente a propósito do nascimento da fisiologia, interessada não somente pelo seu sucesso, mas pelas condições que permitiram ou determinaram o seu aparecimento num momento específico da "história intelectual da civilização". E o encontro com a epistemologia de Bachelard nos anos 50, sem dúvida crucial para a teoria canguilhemiana da história das ciências, marcará uma reformulação daquela problematização, e não o seu abandono. É o que nos indicam essas linhas retiradas do prefácio que Canguilhem escreveu, em 1979, para o livro de François Delaporte sobre a questão da vegetalidade no século XVIII:

É certo que o conhecimento das estruturas e das funções vegetais deve impulsos decisivos aos botanistas do século XVIII. Todas as histórias da botânica o repetem. Mas, para a maioria, elas estão bem distantes de se interrogar sobre as razões e as circunstâncias da invenção pelos naturalistas de suas táticas ou de seus métodos. Para fazer isso, é preciso se interessar, na história de uma ciência, menos pelos seus resultados, celebrados como vitórias, que pelo modo como os problemas, mesmo aqueles não resolvidos, foram colocados. É preciso considerar a ciência como uma empreitada laboriosa de leitura dos fenômenos, dos quais as hipóteses são a grade. A gênese das hipóteses deve, então, ser privilegiada em relação ao recenseamento das observações. ${ }^{55}$

\footnotetext{
54 Claude Debru, "Épistémologie historique et/ou Histoire épistémologique?” em Epistemology and history from Bachelard and Canguilhem to today's history of science, 115.

55 Georges Canguilhem, "Préface" em François Delaporte, Le second règne de la nature (Paris: Éditions des archives contemporaines, 2011), 8.
} 